\title{
Antidotes in Poisoning
}

\author{
Binila Chacko ${ }^{1}$, John V Peter ${ }^{2}$
}

\begin{abstract}
Introduction: Antidotes are agents that negate the effect of a poison or toxin. Antidotes mediate its effect either by preventing the absorption of the toxin, by binding and neutralizing the poison, antagonizing its end-organ effect, or by inhibition of conversion of the toxin to more toxic metabolites. Antidote administration may not only result in the reduction of free or active toxin level, but also in the mitigation of end-organ effects of the toxin by mechanisms that include competitive inhibition, receptor blockade or direct antagonism of the toxin.

Mechanism of action of antidotes: Reduction in free toxin level can be achieved by specific and non-specific agents that bind to the toxin. The most commonly used non-specific binding agent is activated charcoal. Specific binders include chelating agents, bioscavenger therapy and immunotherapy. In some situations, enhanced elimination can be achieved by urinary alkalization or hemadsorption. Competitive inhibition of enzymes (e.g. ethanol for methanol poisoning), enhancement of enzyme function (e.g. oximes for organophosphorus poisoning) and competitive receptor blockade (e.g. naloxone, flumazenil) are other mechanisms by which antidotes act. Drugs such as $\mathrm{N}$-acetyl cysteine and sodium thiocyanate reduce the formation of toxic metabolites in paracetamol and cyanide poisoning respectively. Drugs such as atropine and magnesium are used to counteract the end-organ effects in organophosphorus poisoning. Vitamins such as vitamin K, folic acid and pyridoxine are used to antagonise the effects of warfarin, methotrexate and INH respectively in the setting of toxicity or overdose. This review provides an overview of the role of antidotes in poisoning.

Keywords: Antidote, Binding, Poison, Toxin.

Indian Journal of Critical Care Medicine (2019): 10.5005/jp-journals-10071-23310
\end{abstract}

\section{INTRODUCTION}

Toxicological emergencies are encountered frequently in intensive care unit (ICU) practice, either as a result of drug overdose (accidental or suicidal) or due to drug toxicity secondary to inappropriate drug dosing or drug interactions. In general, toxic agents can be classified into two groups: those for which specific treatment exists and others for which there is no specific therapy. The latter list by far exceeds the former and hence the most important guiding principle in such emergencies is good supportive care while the patient recovers. "Treat the patient, not the toxin" is hence the guiding dictum in clinical toxicology. In a small proportion $(<2 \%)$ of toxins, ${ }^{1}$ antidotes have been identified. It must be stressed that the expected benefit of the antidote must be determined and weighed against the potential side effects and toxicity of the antidote. In severe poisoning, the antidote is only an adjunct to supportive treatment and its use should not distract the physician from delivering adequate attention to airway, breathing, circulation, and decontamination. When antidotes are administered appropriately, they may limit morbidity and mortality as demonstrated in paracetamol and digitalis overdose. ${ }^{2}$ On the other hand, if unavailable or used inappropriately, the patient may suffer adverse effects from the poison or the antidote, respectively.

\section{What is an Antidote?}

The International Programme of Chemical Safety broadly defines an antidote as a therapeutic agent that counteracts the toxic actions of a drug/toxin. ${ }^{3}$ Broadly, antidotes have been looked at as agents that "modify the kinetics of the toxic substance or interfere with its effect at receptor sites." 4 This may be as a result of prevention of absorption, binding, and neutralizing the poison directly, antagonizing its end-organ effect, or inhibition of conversion to more toxic metabolites. ${ }^{5} \mathrm{~A}$ chemical's safety is defined by its therapeutic index or ratio $\left(\mathrm{TD}_{50} / \mathrm{ED}_{50}\right)$, which is the ratio of the toxic
${ }^{1,2}$ Medical Intensive Care Unit, Division of Critical Care, Christian Medical College, Vellore, Tamil Nadu, India

Corresponding Author: Binila Chacko, Medical Intensive Care Unit, Division of Critical Care, Christian Medical College, Vellore, Tamil Nadu, India, Phone: +91 9600272412, e-mail: binilachacko@gmail.com

How to cite this article: Chacko B, Peter JV. Antidotes in Poisoning. Indian J Crit Care Med 2019;23(Suppl 4):S241-S249.

Source of support: Nil

Conflict of interest: None

dose (TD) or lethal dose (LD) to the effective dose (ED). Based on this, an antidote has also been defined as an agent that "increases the mean lethal dose of a toxin."1

\section{How Does an Antidote Work?}

When one thinks of antidotes, one generally considers those that operate through a distinct logical mechanism such as naloxone and flumazenil that function as competitive receptor antagonists or vitamin $\mathrm{K}$ for warfarin overdose to overcome enzyme inhibition. Antidotes, however, have a broader meaning in terms of altering the effect of a toxin. Two main variables impact the harmful effect of a toxin on the body, namely the dose and the duration of exposure to the toxin. ${ }^{1}$ These in turn depend on the type of toxin, the dose, the route of administration, lag time to presentation to a hospital, and pharmacokinetics (absorption, distribution, and elimination).

Thus, four basic mechanisms (Fig. 1) guide antidotal therapy in toxicology that result in the alteration of the toxin load and the duration of exposure and elevate the victim's threshold for toxicity. This includes (a) decreasing the active toxin level, (b) blocking the site of action of the toxin, (c) decreasing the toxic metabolites, and (d) counteracting the effects of the toxin. 


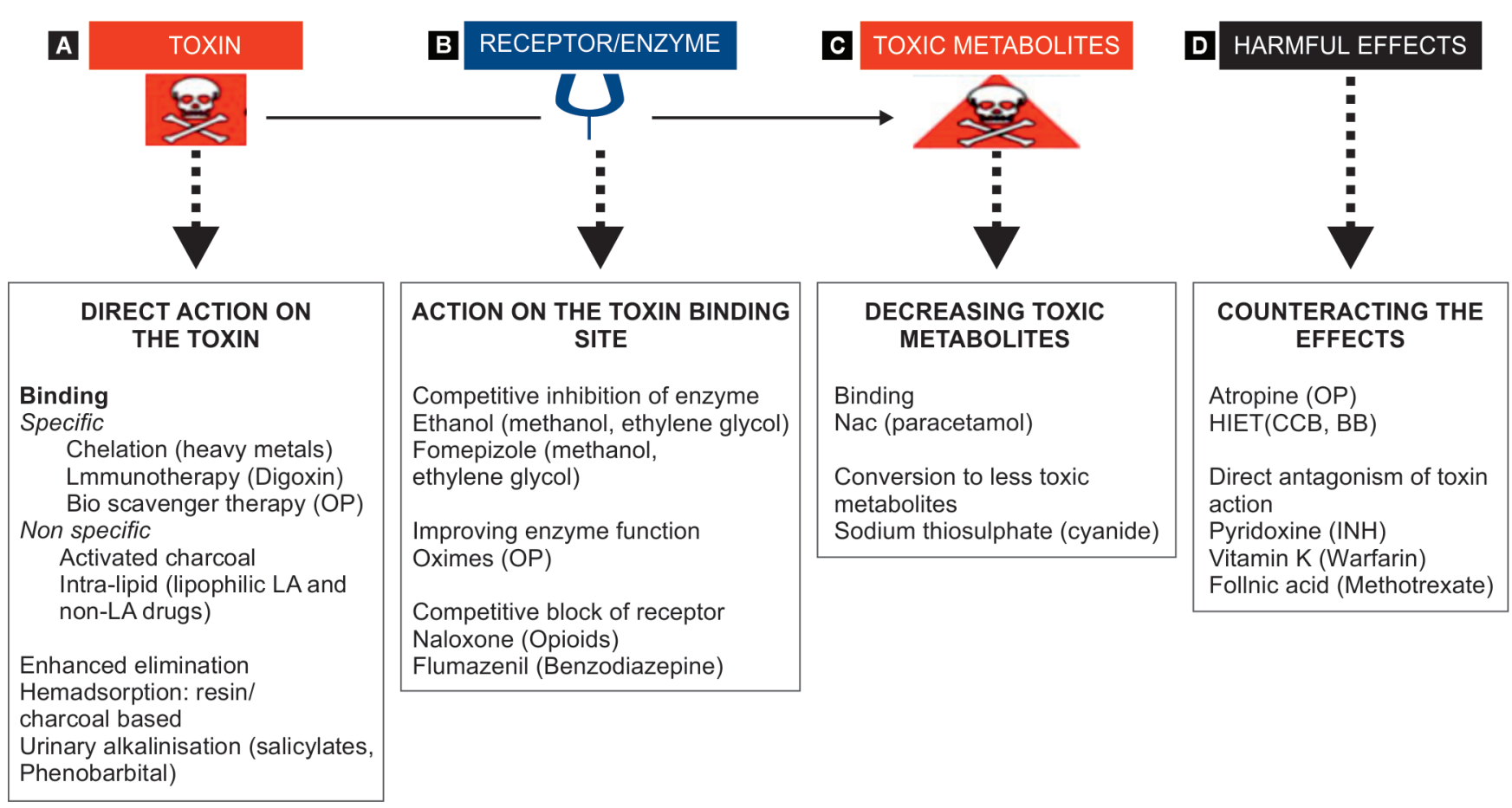

Figs $1 A$ to D: Antidotes act by four predominant mechanisms; (A) Direct action on the toxin involves specific and nonspecific binding and enhanced elimination. Specific binding can be achieved by chelation (e.g., heavy metals), immunotherapy (e.g., digoxin), and bioscavenger therapy (e.g., organophosphorus (OP) compounds). Nonspecific binding occurs with the use of activated charcoal and intralipid therapy (e.g., lipophilic local anesthetics (LA) and non-LA drugs). Enhanced elimination of toxin can be facilitated through urinary alkalization (e.g., salicylates, phenobarbital) and hemadsorption with the use of resin or charcoal; (B) Action on the toxin binding site can be achieved by competitive inhibition of the enzyme (e.g., ethanol or fomepizole for methanol and ethylene glycol poisoning) or by competitive blockade of the receptor (e.g., naloxone for opioid overdose and flumazenil for benzodiazepine overdose; (C) Decreasing toxic metabolites can be done by binding (e.g., $\mathrm{N}$-acetyl cysteine (NAC) as for paracetamol overdose) and conversion to less toxic metabolites (e.g., sodium thiosulphate for cyanide poisoning); (D) Counteracting the effects: drugs such as atropine counteract the muscarinic effects of OP poisoning. High-dose insulin euglycemic therapy (HIET) is used for calcium channel blocker (CCB) and $\beta$-blocker (BB) overdose. Direct antagonism of toxin action is the mechanism for reversing the toxicity of $\mathrm{INH}$ (pyridoxine), warfarin (vitamin $\mathrm{K}$ ), and methotrexate (folinic acid)

\section{Decreasing the Free or Active Toxin Level}

A reduction in the free or active toxin level can be achieved by agents that "bind" to the toxin (Table 1). This binding can be either specific or nonspecific. Specific binding occurs in the form of chelating agents for heavy metal poisoning, Digi-Fab for digoxin overdose, hydroxycobalamin for cyanide poisoning, or bioscavenger therapy (human butyryl cholinesterase) for organophosphorus poisoning, ${ }^{6,7}$ where the antidote enables the formation of inert complexes ${ }^{8}$ that are then eliminated from the body (Table 1).

Activated charcoal has been included in the list of nonspecific antidotes because it can decrease the toxin levels by its high adsorption capacity and by interrupting the enterohepatic recirculation of the toxin. A higher charcoal to drug ratio will more effectively inhibit systemic absorption; while 10:1 is ideal, some reports suggest that a 40:1 charcoal to drug ratio might be superior. Activated charcoal has been in use for over a century and while it has been reported to be the most common form of gastrointestinal decontamination in the poisoned patient, its use has declined from $7.7 \%$ to $5.9 \% .^{9}$ The reason for this is twofold; first, the evidence ${ }^{10,11}$ from randomized controlled trials (RCTs) has failed to show any added benefit of activated charcoal. Second, the complications from its administration, such as charcoal aspiration with pneumonitis ${ }^{12}$ and constipation and bowel obstruction, ${ }^{13}$ preclude widespread use. The position paper on charcoal recommends that "singledose activated charcoal should not be administered routinely in the management of poisoned patients." ${ }^{\prime 9}$ This can however be considered in a patient who has ingested a toxin within an hour of presentation. ${ }^{9}$ Multidose activated charcoal is recommended in lifethreatening ingestions of carbamazepine, dapsone, phenobarbital, quinine, or theophylline. ${ }^{14}$

Lipid sink therapy has also been considered under nonspecific binders since its recognition of benefit in local anesthetic toxicity in rats in $1998 .{ }^{15}$ Intravenous lipid therapy has been in use in humans for both lipophilic local anesthetics and nonlocal anesthetic agents ( $\beta$-blockers, calcium channel blockers, psychotropic drug overdose). This works on the lipid sink principle where lipophilic drugs, with an octanol to water partitioning coefficient of $\log p>2,{ }^{16}$ are trapped in the plasma lipid compartment. Lipid emulsion therapy has also been proposed to have a direct inotropic effect through increase in calcium levels in cardiac myocytes. ${ }^{17}$

Enhancing the elimination of toxins with the use of antidotes can be done either through hemoperfusion techniques (charcoal or resin based) ${ }^{18}$ or urinary alkalinization (targeting a $\mathrm{pH}>7.5$ ) with intravenous sodium bicarbonate therapy. ${ }^{19}$ Hemoperfusion is useful for protein-bound toxins, high lipid solubility, or toxins with a high volume of distribution. Urinary alkalinization is useful for acidic toxins such as salicylates and phenobarbital and acts by increasing ionization of the toxin, thereby limiting their tubular reabsorption. ${ }^{19}$

\section{Action on the Toxin-binding Site}

This can be either at the enzyme level or the receptor level (Table 2). At the enzyme level, the action could be twofold: competitive 


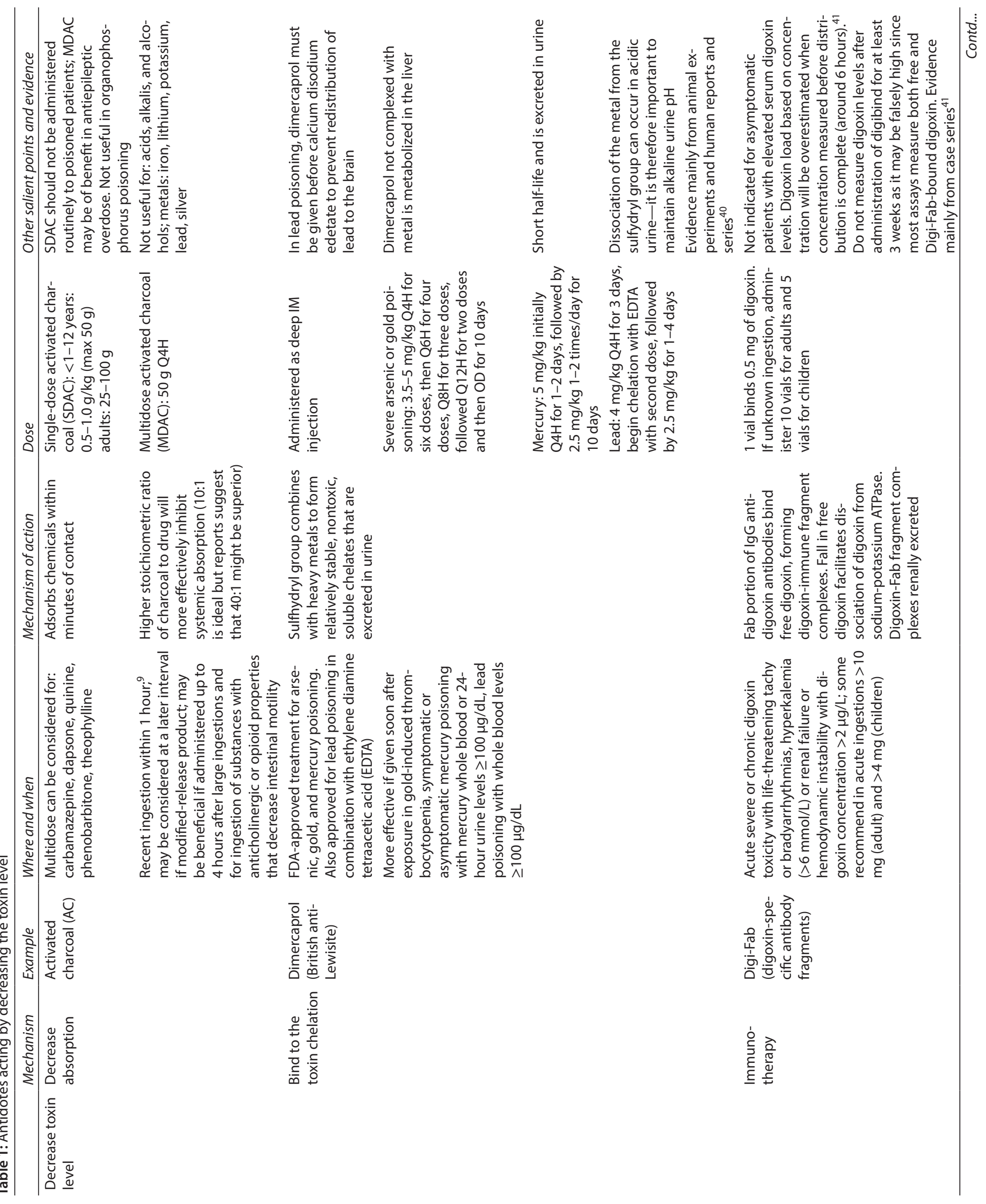




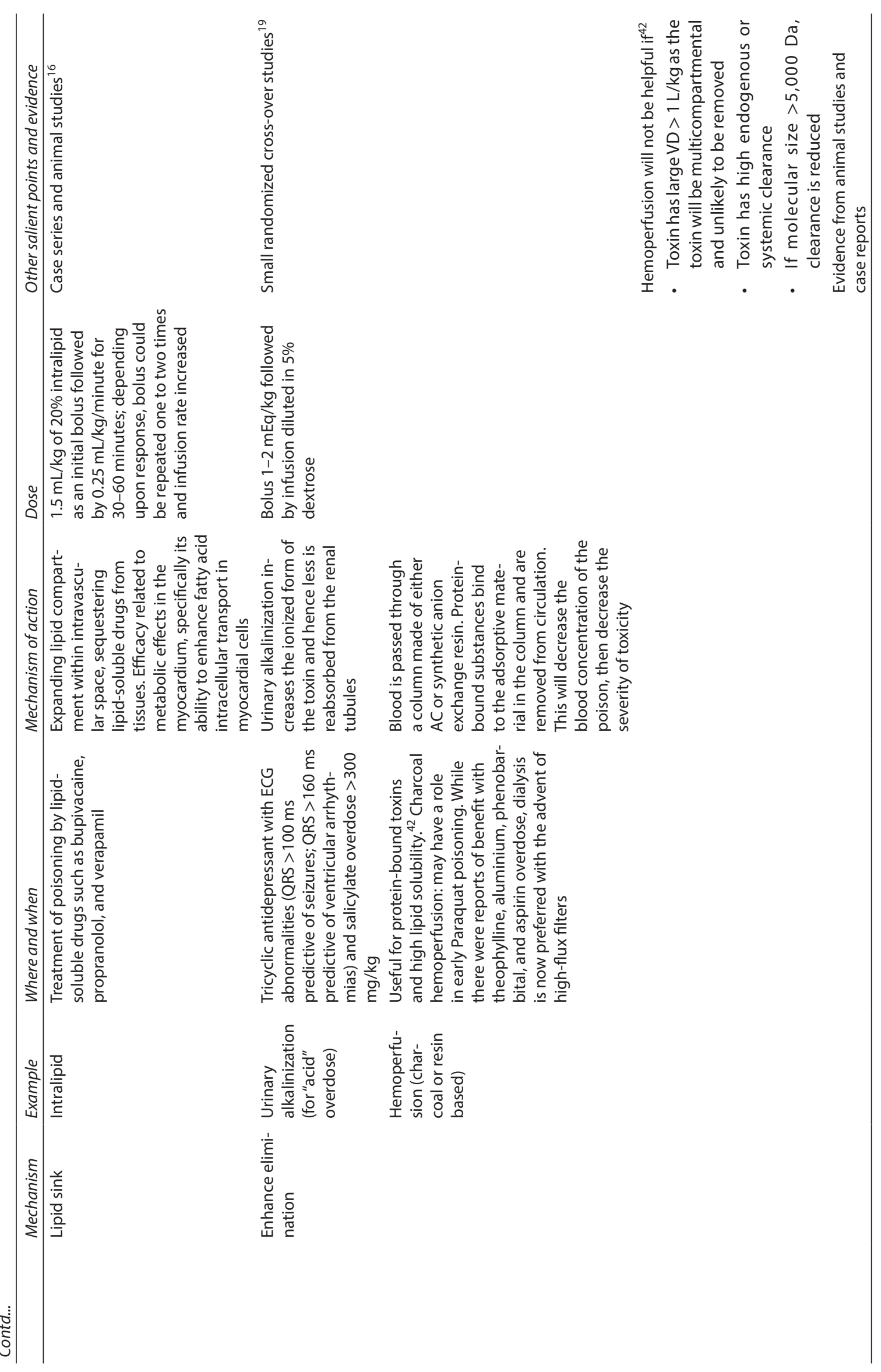




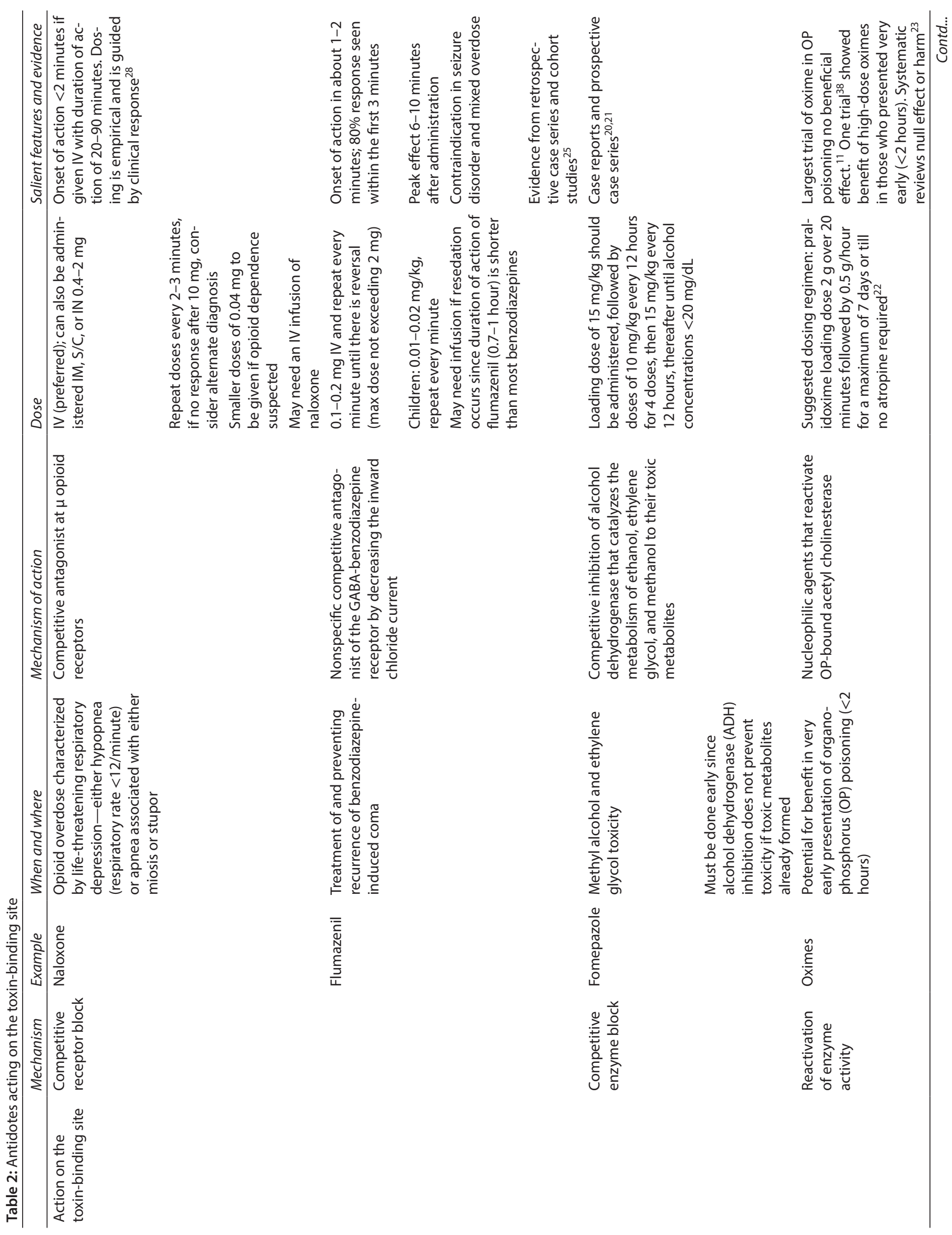




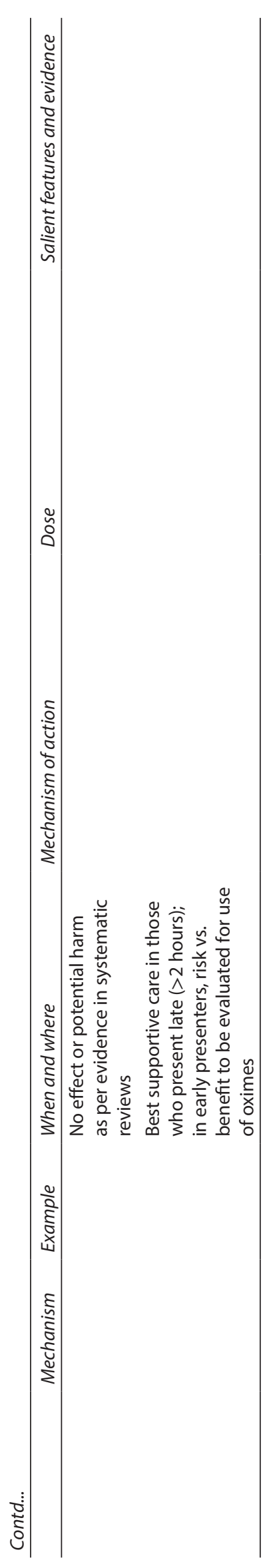

inhibition or reactivation of enzyme activity. The classical example of competitive enzyme inhibition is the use of ethyl alcohol or fomepizole in methyl alcohol or ethylene glycol poisoning. These agents act by competing with methyl alcohol ${ }^{20}$ and ethylene glycol $^{21}$ for alcohol dehydrogenase (ADH), thereby decreasing the formation of toxic metabolites. This must be done early since ADH inhibition does not prevent toxicity if the toxic metabolites are already formed.

Reactivation of enzyme activity in the setting of organophosphorus poisoning is achieved with the use of nucleophilic agents such as oximes that reactivate organophosphorus-bound acetyl cholinesterase. Meta-analysis of studies on oxime therapy in acute organophosphorus poisoning has shown a null effect or potential harm. ${ }^{7}$ While the largest randomized trial of oximes showed clear reactivation of red cell acetylcholinesterase, there was no evidence of improved survival with oxime therapy. ${ }^{22}$ There are several reasons for the failure of oximes in acute organophosphorus poisoning. ${ }^{23}$ More research on this aspect may throw light on possible options of dosing and timing of antidotal therapy in organophosphorus poisoning.

At the receptor level, flumazenil and naloxone are the classical antidotes. Flumazenil is a competitive antagonist at the benzodiazepine site on the GABA-A receptor complex. ${ }^{24}$ This decreases the inward chloride current and thereby reverses CNS and respiratory depression. Flumazenil has been shown to be effective in the treatment of and preventing recurrence of benzodiazepineinduced coma. ${ }^{25-27}$

Flumazenil is contraindicated in patients with unknown or mixed overdose, benzodiazepine tolerance, seizure disorders, or a prolonged QRS interval. Naloxone is a pure opioid antagonist that competes and displaces opioids at opioid receptor sites and has been shown in uncontrolled studies to be useful in opioid reversal. ${ }^{28}$ Given the risk of opioid withdrawal that can happen not only in regular opioid abusers but also with acute opioid toxicity, the recent American Heart Association recommends using the "lowest effective dose" 29 of naloxone.

\section{Decreasing Toxic Metabolites}

Once toxic metabolites are formed, antidotes may be used to either mop up the toxic metabolite or convert the metabolites into a less toxic form (Table 3). $\mathrm{N}$-Acetyl cysteine (NAC) has been used for paracetamol poisoning for the past 50 years. ${ }^{30} \mathrm{~N}$-Acetyl cysteine restores hepatic glutathione stores, which in turn is responsible for conjugating the toxic metabolite, $\mathrm{N}$-acetyl P-benzoquinone imine (NAPQI). This is believed to be the mechanism of prevention of paracetamol-induced hepatic injury. While there are no randomized controlled trials to assess the efficacy of NAC for liver injury prevention, there are several studies ${ }^{31,32}$ that have reported benefit and hence it is considered unethical to perform a RCT.

In cyanide poisoning, sodium thiosulphate ${ }^{33}$ has been found to catalyze the formation of thiocyanate from cyanide by being a sulfhydryl donor to rhodonase enzyme. This is an example of conversion of toxic metabolites to less toxic compounds.

\section{Counteracting the Harmful Effects of the Toxin}

Counteracting the harmful effect of the toxin could be effected in two ways, either by mitigating the effect of the toxin or by direct antagonism of drug action. Atropine, used in organophosphorus poisoning, is an example of an antidote that is used to counter and mitigate the several muscarinic effect of the poison. Several vitamins are used to directly antagonize the effect of a drug or toxin. 

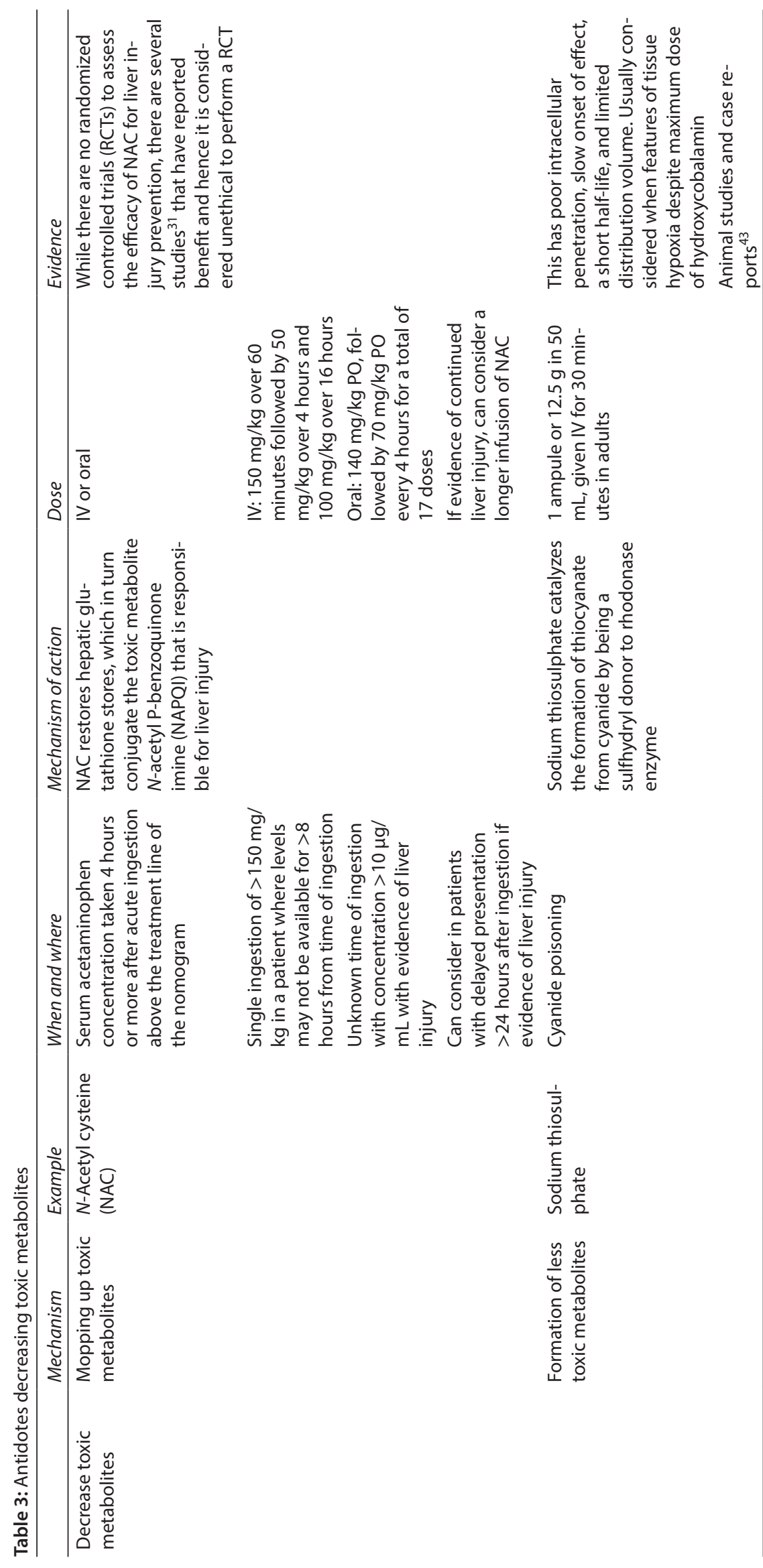
Examples include vitamin $\mathrm{K}$ for warfarin overdose, pyridoxine $\mathrm{e}^{34}$ for isoniazid (INH) overdose, and folinic acid for methotrexate toxicity. ${ }^{35}$ Pyridoxine binds to INH, replaces stores of pyridoxine, and facilitates the production of $\gamma$-amino butyric acid (GABA) that helps in controlling seizures.

\section{When Should the Antidote be Administered?}

The "benefit from antidotes is generally time-dependent and uncertain." ${ }^{\prime 36}$ It is difficult to give a prescribed approach to guide the decision to administer an antidote in a toxicological emergency as this depends on the lag time to presentation, toxicokinetics properties, and the mechanism of action of the antidote.

Antidotes that decrease the toxin level by reducing absorption or by adsorption (binding agents) at the receptor/enzyme level are generally beneficial if administered early. On the other hand, antidotes that modify the toxic metabolites or modulate the effects (either symptomatic or direct antagonism of the effect of the toxin) could be given at variable times. Tables 1 to 3 provide an overview of the various mechanisms of action of antidotes, the clinical setting where it could be used, and the dosing of common antidotes.

\section{How Long Should the Antidote be Administered for?}

The duration of antidotal therapy depends on the type of toxin consumed, the estimated dose that the individual has been exposed to, route of exposure, clinical features of toxicity, half-life, and pharmacokinetics as well as the risk vs benefit for the use of the antidote. In case the antidote has a short half-life, an infusion may need to be started particularly if symptoms of toxicity resurface.

\section{What is the Evidence of Efficacy of Antidotes?}

Results from animal studies, human case reports, pharmacokinetic data, expert opinion, and logic have generally guided the timing, indications, and dosing of antidotes. Although there are some RCTs that have explored the role of activated charcoal in poisoning, ${ }^{37}$ there is a paucity of RCTs on specific antidotes in poisoning other than organophosphorus poisoning. ${ }^{38,39}$ The lack of high-level evidence should not deter the clinician from considering a particular antidote as long as the benefits outweigh the risks.

\section{Conclusion}

Successful outcomes in a toxicological emergency not only require appropriate management of airway, breathing, and circulation but also the knowledge and application of appropriate antidotal therapy. The latter may result in reducing the intensity of the poisoning and improving outcomes.

\section{References}

1. Karami M, Estachri MRAE. Principles of toxicotherapy: general and specific therapy. Sch Acad J Pharm 2015;4(3):153-156.

2. Wang RY, KazziZN. Editorial: antidotes and rescue therapies. Curr Pharm Biotechnol 2012;13(10):1914-1916. DOI: 10.2174/138920112802273164.

3. Jacobsen D. The relative efficacy of antidotes. J Toxicol Clin Toxicol 2008;33(6):705-708. DOI: 10.3109/15563659509010633.

4. De Garbino JP, Haines JA, Jacobsen D, Meredith T. Evaluation of antidotes: activities of the International Programme on
Chemical Safety. J Toxicol Clin Toxicol 2009;35(4):333-343. DOI: 10.3109/15563659709043364.

5. Salyer SW. Toxicology emergencies. In: Salyer SW, ed. Essential Emergency Medicine, ch. 17 Philadelphia: W.B. Saunders; 2007. pp. 923-1049.

6. Pichamuthu K, Jerobin J, Nair A, John G, Kamalesh J, Thomas K, et al. Bioscavenger therapy for organophosphate poisoning - an open-labeled pilot randomized trial comparing fresh frozen plasma or albumin with saline in acute organophosphate poisoning in humans. Clin Toxicol (Phila) 2010;48(8):813-819. DOI: 10.3109/15563650.2010.518970.

7. Peter JV, Moran JL, Graham PL. Advances in the management of organophosphate poisoning. Expert Opin Pharmacother 2007;8(10):1451-1464. DOI: 10.1517/14656566.8.10.1451.

8. Pillay VV. Current views on antidotal therapy in managing cases of poisoning and overdose. J Assoc Physicians India 2008;56:881-892.

9. Chyka PA, Seger D, Krenzelok EP, Vale JA, American Academy of Clinical Toxicology, European Association of Poisons Centres and Clinical Toxicologists. Position paper: single-dose activated charcoal. Clin Toxicol (Phila) 2005;43(2):61-87. DOI: 10.1081/CLT-51867.

10. Merigian KS, Blaho KE. Single-dose oral activated charcoal in the treatment of the self-poisoned patient: a prospective, randomized, controlled trial. Am J Ther 2002;9(4):301-308. DOI: 10.1097/00045391200207000-00007.

11. Eddleston M, Juszczak E, Buckley NA, Senarathna L, Mohamed F, Dissanayake W, et al. Multiple-dose activated charcoal in acute selfpoisoning: a randomised controlled trial. Lancet 2008;371(9612): 579-587. DOI: 10.1016/S0140-6736(08)60270-6.

12. Do SI, Park S, Ha H, Kim HJ. Fatal pulmonary complications associated with activated charcoal: an autopsy case. Basic Appl Pathol 2009;2(3):106-108. DOI: 10.1111/j.1755-9294.2009.01048.x.

13. Goulbourne KB, Cisek JE. Small-bowel obstruction secondary to activated charcoal and adhesions. Ann Emerg Med 1994;24(1): 108-110. DOI: 10.1016/S0196-0644(94)70170-9.

14. Brent J, Jaeger A, McGuigan M, Meulenbelt J, Tenenbein M, Bradberry $\mathrm{S}$, et al. Position statement and practice guidelines on the use of multi-dose activated charcoal in the treatment of acute poisoning. JToxicol Clin Toxicol 1999;37(6):731-751. DOI: 10.1081/CLT-100102451.

15. Weinberg GL, VadeBoncouer T, Ramaraju GA, Garcia-Amaro MF, Cwik MJ. Pretreatment or resuscitation with a lipid infusion shifts the doseresponse to bupivacaine-induced asystole in rats. Anesthesiology 1998;88(4):1071-1075. DOI: 10.1097/00000542-199804000-00028.

16. Ozcan MS, Weinberg G. Intravenous lipid emulsion for the treatment of drug toxicity. J Intensive Care Med 2012;29(2):59-70. DOI: 10.1177/0885066612445978.

17. Rothschild L, Bern S, Oswald S, Weinberg G. Intravenous lipid emulsion in clinical toxicology. Scand J Trauma Resusc Emerg Med 2010;18:51. DOI: 10.1186/1757-7241-18-51.

18. Gil H-W, Kim S-J, Yang J-O, Lee E-Y, Hong S-Y. Clinical outcome of hemoperfusion in poisoned patients. Blood Purif 2010;30(2):84-88. DOI: 10.1159/000318585.

19. Proudfoot AT, Krenzelok EP, Vale JA. Position paper on urine alkalinization. J Toxicol Clin Toxicol 2004;42(1):1-26. DOI: 10.1081/ CLT-120028740.

20. Barceloux DG, Bond GR, Krenzelok EP, Cooper H, Vale JA, American Academy of Clinical Toxicology Ad Hoc Committee on the Treatment Guidelines for Methanol Poisoning. American Academy of Clinical Toxicology practice guidelines on the treatment of methanol poisoning. J Toxicol Clin Toxicol 2002;40(4):415-446. DOI: 10.1081/ CLT-120006745.

21. Miller H, Barceloux DG, Krenzelok EP, Olson K, Watson W. American Academy of Clinical Toxicology practice guidelines on the treatment of ethylene glycol poisoning. J Toxicol Clin Toxicol 2015;37(5):537-560. DOI: 10.1081/CLT-100102445.

22. Eddleston M, Eyer P, Worek F, Juszczak E, Alder N, Mohamed F, et al. Pralidoxime in acute organophosphorus insecticide poisoning--a randomised controlled trial. PLoS Med 2009;6(6):e1000104. DOI: 10.1371/journal.pmed.1000104. 
23. Peter JV, Moran JL, Graham P. Oxime therapy and outcomes in human organophosphate poisoning: an evaluation using meta-analytic techniques. Crit Care Med 2006;34(2):502-510. DOI: 10.1097/01. CCM.0000198325.46538.AD.

24. Hoffman EJ, Warren EW. Flumazenil: a benzodiazepine antagonist. Clin Pharm 1993;12(9):641-656; quiz 699-701.

25. Kreshak AA, Cantrell FL, Clark RF, Tomaszewski CA. A poison center's ten-year experience with flumazenil administration to acutely poisoned adults. J Emerg Med 2012;43(4):677-682. DOI: 10.1016/ j.jemermed.2012.01.059.

26. Weinbroum AA, Flaishon R, Sorkine P, Szold O, Rudick V. A risk-benefit assessment of flumazenil in the management of benzodiazepine overdose. Drug Saf 1997;17(3):181-196. DOI: 10.2165/00002018199717030-00004.

27. Weinbroum A, Rudick V, Sorkine P, Nevo Y, Halpern P, Geller E, et al. Use of flumazenil in the treatment of drug overdose. Crit Care Med 1996;24(2):199-206. DOI: 10.1097/00003246-19960200000004.

28. Rzasa Lynn R, Galinkin JL. Naloxone dosage for opioid reversal: current evidence and clinical implications. Ther Adv Drug Saf 2018;9(1):63-88. DOI: 10.1177/2042098617744161.

29. Lavonas EJ, Drennan IR, Gabrielli A, Heffner AC, Hoyte CO, Orkin AM, et al. Part 10: special circumstances of resuscitation: 2015 American Heart Association guidelines update for cardiopulmonary resuscitation and emergency cardiovascular care. Circulation 2015;132(18 Suppl 2):S501-S518. DOI: 10.1161/CIR.0000000000000264.

30. Piperno E, Mosher AH, Berssenbruegge DA, Winkler JD, Smith RB. Pathophysiology of acetaminophen overdosage toxicity:implications for management. Pediatrics 1978;62(5 Pt 2 Suppl):880-889.

31. Rumack BH, Peterson RC, Koch GG, Amara IA. Acetaminophen overdose. 662 cases with evaluation of oral acetylcysteine treatment. Arch Intern Med 1981;141(3 Spec No):380-385. DOI: 10.1001/archi nte.1981.00340030112020.

32. Prescott LF, Ballantyne A, Proudfoot AT, Park J, Adriaenssens P. Treatment of paracetamol (acetaminophen) poisoning with $\mathrm{N}$-acetylcysteine. Lancet 1977;310(8035):432-434. DOI: 10.1016/ S0140-6736(77)90612-2.
33. Curry SC, Carlton MW, Raschke RA. Prevention of fetal and maternal cyanide toxicity from nitroprusside with coinfusion of sodium thiosulfate in gravid ewes. Anesth Analg 1997;84(5):1121-1126. DOI: 10.1213/00000539-199705000-00031.

34. Lheureux P, Penaloza A, Gris M. Pyridoxine in clinical toxicology: a review. Eur J Emerg Med 2005;12(2):78-85. DOI: 10.1097/00063110200504000-00007.

35. HowardSC,McCormickJ,PuiC-H,Buddington RK, Harvey RD. Preventing and managing toxicities of high-dose methotrexate. Oncologist 2016;21(12):1471-1482. DOI: 10.1634/theoncologist.2015-0164.

36. Buckley NA, Dawson AH, Juurlink DN, Isbister GK. Who gets antidotes? choosing the chosen few. Br J Clin Pharmacol 2016;81(3):402-407. DOI: 10.1111/bcp.12894.

37. Cooper GM, Le Couteur DG, Richardson D, Buckley NA. A randomized clinical trial of activated charcoal for the routine management of oral drug overdose. QJM 2005;98(9):655-660. DOI: 10.1093/qjmed/hci102.

38. Pawar KS, Bhoite RR, Pillay CP, Chavan SC, Malshikare DS, Garad SG Continuous pralidoxime infusion versus repeated bolus injection to treat organophosphorus pesticide poisoning: a randomised controlled trial. Lancet 2006;368(9553):2136-2141. DOI: 10.1016/ S0140-6736(06)69862-0.

39. Johnson S, Peter JV, Thomas K, Jeyaseelan L, Cherian AM. Evaluation of two treatment regimens of pralidoxime $(1 \mathrm{~g}$ single bolus dose vs $12 \mathrm{~g}$ infusion) in the management of organophosphorus poisoning. J Assoc Physicians India 1996;44(8):529-531.

40. Kosnett MJ. The role of chelation in the treatment of arsenic and mercury poisoning. J Med Toxicol 2013;9(4):347-354. DOI: 10.1007/ s13181-013-0344-5.

41. Chan BSH, Buckley NA. Digoxin-specific antibody fragments in the treatment of digoxin toxicity. Clin Toxicol 2014;52(8):824-836. DOI: 10.3109/15563650.2014.943907.

42. Ghannoum M, Bouchard J, Nolin TD, Ouellet G, Roberts DM. Hemoperfusion for the treatment of poisoning: technology, determinants of poison clearance, and application in clinical practice. Semin Dial 2014;27(4):350-361. DOI: 10.1111/sdi.12246.

43. Borron SW, Baud FJ. Antidotes for acute cyanide poisoning. Curr Pharm Biotechnol 2012;13(10):1940-1948. DOI: 10.2174/138920112802273182. 